\title{
Slimme sturing van publiek-private samenwerking bij publieke infrastructuur ${ }^{*}$
}

\author{
Joop Koppenjan, Erik Hans Klijn, Rianne Warsen \& José Nederhand
}

Bij de aanleg en het beheer van publieke infrastructuur heeft het Rijk de laatste jaren voor publiek-private samenwerking, en met name voor het $\operatorname{DBFM}(\mathrm{O})$-contract, als slim arrangement gekozen: langlopende contracten waarbij het ontwerp (D), de bouw (B), de financiering ( $F)$, het onderhoud (M) en vaak ook de exploitatie $(O)$ integraal worden uitbesteed aan een privaat consortium. Met deze slimme $\operatorname{DBFM}(O)$-contracten wordt getracht de sterke punten van overheid en de markt te combineren om de steeds grotere en complexere publieke opgaven aan te kunnen. De praktijk blijkt echter weerbarstig: recent hebben Rijkswaterstaat en een aantal private partijen het initiatief genomen tot wat zij noemden 'een nieuwe marktvisie'. Daarin stellen ze voor om publiek-private samenwerking op een nieuwe leest te schoeien. Onder andere naar aanleiding van problemen bij DBFM(O)-projecten pleiten zij voor meer aandacht voor relationele aspecten van samenwerking, zoals houding, openheid en vertrouwen. Ook onderzoek laat zien dat het succes van $\operatorname{DBFM}(O)$-projecten niet bepaald wordt door het contract of een strikt contractmanagement. Slimme sturing vraagt om meer: om een verschuiving van een financieel-economisch georiënteerde contractuele benadering naar een meer sociologisch geïnspireerde relationele manier van sturen.

\section{Inleiding ${ }^{1}$}

In Nederland gebruikt het Rijk publiek-private samenwerking (PPS) als 'de' governance-strategie om grote publieke infrastructuurprojecten te realiseren. Het idee

* Joop Koppenjan is hoogleraar bestuurskunde aan de Erasmus Universiteit Rotterdam. Hij doet onderzoek naar beleidsnetwerken, beleidsprocessen, publiek management en innovatie. Erik Hans Klijn is professor in de bestuurskunde aan de Erasmus Universiteit Rotterdam. Zijn onderzoek richt zich op complexe besluitvorming, netwerkmanagement, publiek-private samenwerking, branding en de invloed van media op governance-netwerken. Rianne Warsen is promovendus in de bestuurskunde aan de Erasmus Universiteit Rotterdam. Zij doet onderzoek naar publiek-private samenwerking, prestaties, collaborative governance en de dynamiek tussen contractuele en relationele aspecten in samenwerkingsprojecten. José Nederhand is promovendus in de bestuurskunde aan de Erasmus Universiteit Rotterdam. Haar onderzoek focust zich op zelforganisatie, sociaal ondernemerschap, coproductie en publiek-privaatmaatschappelijke samenwerking.

1 Deze bijdrage is geschreven in het kader van het door de NWO gefinancierde onderzoeksproject 'Governance for Smartening Public Private Partnerships' Dit onderzoek wordt in de periode 2015-2019 uitgevoerd door de Erasmus Universiteit Rotterdam en de Universiteit Twente in samenwerking met Rijkswaterstaat, rebel Group, Reset Management, Twijnstra Gudde, Deltares en de Nederlandse School voor Openbaar Bestuur (NSOB). Zie: http://smartgovernancepartnerships.org. 
is dat door intensieve samenwerking tussen publieke en private actoren betere en meer innovatieve infrastructurele werken en diensten gerealiseerd kunnen worden voor minder geld (Sanders, 2018; Hodge, Greve, \& Boardman, 2010). Publiekprivate samenwerking is op zichzelf niets nieuws en komt in vele vormen in onze samenleving voor. In de wereld van publieke infrastructuur worden er specifieke arrangementen mee aangeduid die afwijken van de traditionele wijze van contractering. Onder leiding van het ministerie van Financiën is bij de vormgeving van PPS op rijksniveau het voorbeeld van het Private Finance Initiative in het Verenigd Koninkrijk gevolgd. Dat leidde tot een voorkeur voor $\operatorname{DBFM}(\mathrm{O})$-contracten: geïntegreerde, langlopende contracten, waarbij de private partijen ook de financiering van de projecten voor hun rekening nemen (Klijn, 2009; Koppenjan \& De Jong, 2018). Deze contracten worden vooral gebruikt bij de aanleg en het beheer van publieke infrastructuur zoals wegen, waterwerken en publieke gebouwen. Het oogmerk van deze contracten is het combineren van risico's, kosten en opbrengsten zodat deze door zowel publieke als private partijen gedeeld worden.

Van PPS als slim arrangement wordt veel verwacht. Waar het overheidsbudget beperkt is, brengt private financiering de realisatie van tal van infrastructurele ambities binnen bereik. De innovatiekracht van het bedrijfsleven kan resulteren in het gebruik van innovatieve methoden voor ontwerp, bouw en beheer. Omdat private bedrijven de financiële risico's dragen en beter zijn in management en risicobeheer, behoren budget- en planningsoverschrijdingen tot het verleden. Aanbestedingen in concurrentie resulteren in verzakelijkte verhoudingen, betere plannen en een innovatievere, competitieve bouwsector (Kenniscentrum PPS, 1998; Van Ham \& Koppenjan, 2002; Commissie Private Financiering van infrastructuur, 2008; Ministerie van Financiën, 2016). Niet alleen in Nederland wordt veel van PPS verwacht; ook elders wordt PPS gezien als een 'marriage made in heaven' (Hodge \& Greve, 2005). Inmiddels is duidelijk geworden dat dit partnerschap niet automatisch tot de gewenste resultaten leidt. Aan ieder huwelijk moet worden gewerkt, en PPS vormt daarop geen uitzondering. Er spelen specifieke mechanismen een rol die het succes en falen van $\operatorname{DBFM}(\mathrm{O})$-projecten in de wereld van de publieke infrastructuur beïnvloeden. In dit artikel proberen we aan de hand van theorie, praktijkervaringen en onderzoekbevindingen deze mechanismen te doorgronden.

\section{$\operatorname{DBFM}(\mathrm{O})$ contracten als slim arrangement}

Zoals aangegeven zijn $\operatorname{DBFM}(\mathrm{O})$-contracten geïntegreerde en langlopende contracten. Geïntegreerde contracten maken de risico-overdracht naar private partijen eenvoudiger en maken hen verantwoordelijk voor alle fasen in het project. Bedrijven zijn hierdoor gedwongen consortia van ontwikkelaars, bouwers, financiers en exploitanten te vormen waarin de benodigde kennis en middelen samengebracht worden.

Omdat dit consortium het project zelf financiert, ontstaat een prikkel om in het ontwerp naar innovaties te zoeken die tot kostenreducties en optimalisaties in de latere fasen leiden, is de algemeen gedeelde opvatting (zie Algemene Rekenkamer, 
2013). Zo is er een prikkel om gebouwen op een meer duurzame manier te ontwerpen. Door meer investeringen aan de voorkant van het project te doen kunnen kosten in de exploitatiefase worden gereduceerd. Op deze manier realiseren $\operatorname{DBFM}(\mathrm{O})$-contracten ontwerp-optimalisaties, efficiencywinsten en meerwaarde (hetzelfde project tegen een lagere prijs, of meer functionaliteiten tegen eenzelfde prijs). De lange looptijd stelt private partijen in staat hun investering terug te verdienen. In Nederland gebeurt dat veelal doordat de overheid de private partijen op basis van beschikbaarheid van de infrastructuur betaalt. Soms, zoals bij de bovenbouw van de Hoge Snelheidslijn, betalen ook gebruikers een periodiek bedrag. Op deze manier ontstaan sterke financiële prikkels voor private partijen om de beloofde prestatie op tijd en binnen planning en scope te leveren (Algemene Rekenkamer, 2013).

In het bijzonder Rijkswaterstaat en het Rijksvastgoedbedrijf werken met $\operatorname{DBFM}(\mathrm{O})$-contracten. ${ }^{2}$ In 2016 waren 37 rijksprojecten met deze contracten tot stand gebracht, met een totale waarde 37 miljard euro. De meerwaarde die op deze manier gerealiseerd is, betreft volgens het ministerie van Financiën 1,5 miljard euro (Ministerie van Financiën, 2016). Bekende projecten die op deze wijze tot stand zijn gebracht, zijn onder meer de verbouwing van het ministerie van Financiën en de Kromhout Kazerne in Utrecht, en de realisatie van het Nationaal Militair Museum in Soesterberg, de A59 Den Bosch-Oss, de tweede Coentunnel, de A15 Maasvlakte-Vaanplein, de Waterzuivering Harnaspolder en de nieuwe zeesluis bij IJmuiden. Het beleid van het Ministerie van Financiën is om de toepassing van deze contractvormen ook bij andere ministeries en lagere overheden te stimuleren (Ministerie van Financiën, 2016).

\section{Problemen bij DBFM(O)}

Alhoewel het ministerie van Financiën (2015) in zijn voortgangsrapportages stelt dat de toepassing van $\mathrm{DBFM}(\mathrm{O})$-contracten heeft geleid tot succesvolle projecten, kampen sommige projecten met belangrijke problemen. De lange looptijd van de projecten blijkt keerzijden te hebben. Bestaande arrangementen en contracten bieden onvoldoende mogelijkheden om in te spelen op snelle technologische ontwikkelingen en innovaties op het gebied van infrastructuur (bijv. waar het gaat om het gebruik van informatietechnologie en big data). Daarnaast leidden technische en financiële tegenvallers tot conflicten tussen overheid en bedrijfsleven, zoals in het geval van de tweede Coentunnel, de A15 Maasvlakte-Vaanplein en recentelijk de zeesluis IJmuiden. Tegenslagen brachten een aantal bedrijven aan de rand van de financiële afgrond, of resulteerden in faillissementen. Tegelijkertijd meende de overheid dat deze financiële problemen door de markt zelf opgelost dienden te worden. Door de financiële crisis en de achterblijvende vraag hadden, volgens de overheid, consortia om opportunistische redenen tegen te lage bedragen ingeschreven. Vandaar dat zij gedurende het project in de problemen

2 Rijkswaterstaat gebruikt overwegend DBFM-contracten waar de exploitatie (de 'O') geen deel van uitmaakt. De exploitatie houdt Rijkswaterstaat als netbeheerder in eigen hand. Bij rijksgebouwen is de exploitatie wel onderdeel van het contract. 
kwamen. Consortia meenden evenwel dat het onterecht was dat zij alleen voor deze onverwachte financiële tegenslagen moesten opdraaien. Zij vonden dat de overheid moest bijspringen. Het gevolg: vechtprojecten die resulteerden in stagnaties, kostenoverschrijdingen en slechte relaties (Rijkswaterstaat, 2016a).

Uit deze voorbeelden blijkt al dat de verwachte voordelen (meerwaarde en innovatie) van PPS niet altijd worden bereikt door alleen de kenmerken van het $\operatorname{DBFM}(\mathrm{O})$-contract en de daarin gespecificeerde risicoverdeling, performance criteria, het monitoringsregime en het betalingsmechanisme. Deze ervaringen in de praktijk worden bevestigd door een survey-onderzoek (gehouden medio 2014) onder publieke en private managers van alle toen bekende PPP-projecten. In dit onderzoek werd geen positieve relatie gevonden tussen contractkenmerken, zoals de lengte van het contract en de sanctiemogelijkheden, en de uitkomsten van PPP projecten. Sanctiemogelijkheden bleken zelfs een negatief effect te hebben (Klijn \& Koppenjan, 2016). Ook was er geen relatie tussen contractkenmerken en innovatie. Wel werd een duidelijke relatie vastgesteld tussen vertrouwen en management enerzijds en uitkomsten anderzijds (Warsen et al., 2018). PPS-projecten waarin meer vertrouwen tussen partijen bestaat en waarin de relatie tussen publieke en private partijen meer en actiever gemanaged wordt, presteren gemiddeld genomen beter dan projecten waar dit niet het geval is (zie Warsen et al., 2018). Ander onderzoek komt tot overeenkomstige bevindingen (Steijn et al., 2011; Kort et al., 2016).

Het is dus niet verwonderlijk dat na de ervaringen van de afgelopen jaren en de conflicten bij PPS-projecten, publieke en private partijen in de bouwsector in 2016 gezamenlijk het initiatief genomen hebben om de onderlinge samenwerking rond de realisatie en het beheer van publieke infrastructuur op een nieuwe leest te schoeien: de nieuwe marktvisie (Rijkswaterstaat, 2016a en 2016b.). De marktvisie beoogt een verschuiving van een overwegend contractuele benadering van PPS naar een meer sociale, relationele. Het is een poging tot slimmere sturing van de samenwerking.

Met de omarming van de marktvisie geven publieke en private partijen aan de beperkingen van de sterk contractuele, financiële en economische oriëntatie op PPS als een probleem te ervaren. In hun zoektocht naar een nieuwe manier om samenwerking te realiseren benadrukken zij het belang van de kwaliteit van relaties, van openheid, transparantie en vertrouwen. Door de relationele component meer aandacht te geven wordt er gestreefd naar een betere risicoverdeling, waarbij partners elkaars risico's kennen en elkaar ondersteunen in het beheersen van deze risico's. Oogmerk is ook een eerlijke prijsvorming met realistische marges voor bedrijven. Die zouden moeten afzien van opportunistische biedingen. Om dit te bereiken is een andere houding van zowel publieke als private partijen nodig (Rijkswaterstaat, $2016^{\mathrm{A}}$ ). 


\section{Verschuiving in sturingsmechanismen: van contractuele naar relationele sturing}

Met de nieuwe marktvisie zoeken publieke en private partijen in de wereld van de publieke infrastructuur naar nieuwe samenwerkings- en sturingsprincipes die veel meer een relationele dan een economische grondslag kennen. Het DBFM(O)contract is sterk gebaseerd op de principes van de institutionele economie (Hazeu, 2007). Die veronderstelt rationaliteit en calculerend gedrag van actoren. Deze hanteren een 'logic of consequences': zij kiezen op basis van hun belangen en aanwezige (externe) prikkels de voor hen meest voordelige gedragingen. Contractuele afspraken, betalingsmechanismen en sancties moeten de juiste prikkelstructuur creëren om private partijen hun bijdrage aan publieke projecten en diensten te laten leveren. Daarentegen leunt een relationele benadering op een meer sociologisch geïnspireerde logica. Volgens deze logica laten actoren zich niet alleen door belangen en prikkels leiden, maar ook door normen en waarden. Zij kiezen gedrag op basis van de logica van 'appropriateness': van wat zij juist en 'passend' vinden. Zij zijn daardoor ook gevoelig voor andere sturingswijzen. Behalve door externe prikkels worden zij door interne motieven geleid, en spelen zingeving en het belang van de private of publieke zaak een belangrijke rol. Ook de rol van de groep waartoe ze behoren en het team waarbinnen ze werken, doen ertoe, evenals vertrouwen. Relationele sturing is daarom gericht op het bevorderen van interactie, het delen van informatie, inzichten en verwachtingen, het versterken van een gezamenlijke identiteit en onderling vertrouwen (Sanders, 2018). De marktvisie benadrukt kortom een heel ander mechanisme voor samenwerking en sturing dan het economisch georiënteerde sturingsidee dat aan het $\mathrm{DBFM}(\mathrm{O})$ contract ten grondslag ligt. Deze mechanismen zijn natuurlijk ideaaltypen die in de werkelijkheid in een mengvorm voorkomen (zie ook Hueskes et al., 2016; Sanders, 2017). Zo heeft Rijkswaterstaat aangegeven dat de marktvisie voor $\operatorname{DBFM}(\mathrm{O})$-projecten niet betekent dat het streven naar concurrentie of het gebruik van standaardcontracten wordt losgelaten. Wel zal de risicoverdeling aangepast worden, en wordt ingezet op verbeterde samenwerking, open en transparante communicatie en het vermijden van opportunistisch gedrag (Rijkswaterstaat, $2016^{\mathrm{B}}$ ).

Aangezien de huidige PPS-projecten vooralsnog voornamelijk gebaseerd zijn op omvangrijke contracten, is het de vraag of, en zo ja, welke combinaties van relationele en contractuele benaderingen mogelijk zijn.

\section{Slimme sturing: drie verschillende paden naar excellente performance in PPS}

Om te onderzoeken hoe contractuele en relationele sturing samengaan, hebben de auteurs van dit artikel een studie gedaan waarin 25 PPS-projecten in Nederland en Vlaanderen zijn vergeleken. Op basis van interviews met 74 publieke en private professionals, betrokken bij deze projecten, analyseerden wij met behulp van een Qualitative Comparative Analysis (QCA) welke combinaties van harde, contractuele condities en van meer 'zachte, relationele' condities aanwezig waren 
bij PPS-projecten met uitstekende prestaties (zie ook Warsen et al., 2017 voor de uitgebreide resultaten). ${ }^{3}$ Eerder onderzoek naar inter-organisationele samenwerking suggereert dat contractuele en relationele condities complementair zijn, en elkaar dus kunnen aanvullen voor een goede samenwerking (Poppo \& Zenger, 2002). Ook in de praktijk lijkt een combinatie waarschijnlijk. Ondanks de focus van de Marktvisie op een meer relationele benadering zullen contracten onderdeel blijven van publiek-private samenwerking. Een deel van de gekozen condities vertegenwoordigen daarom het contract, en de toepassing van dit contract: risicoallocatie en strikt contractmanagement. De risicoverdeling bepaalt welke verantwoordelijkheden overgeheveld worden van de publieke naar de private partner, en heeft zodoende een grote invloed op het project. Strikt contractmanagement verwijst naar de manier waarop het contract gehandhaafd wordt in de praktijk, waarbij we ons voornamelijk focussen op de toepassing van boetes bij tekortschietende prestaties. De meer relationele condities in het onderzoek zijn vertrouwen en conflictmanagement. Vertrouwen wordt in veel onderzoek als kritieke succesfactor genoemd. Het is in staat om opportunistisch gedrag te voorkomen, en partijen te bewegen tot informatiedeling en investeringen in het project. Conflictmanagement draait om de manier waarop onenigheden en verschil van inzicht opgelost worden. Het betreft een procesmatige conditie, die verder gaat dan de traditionele 'escalatieladder' die in de standaardcontracten opgenomen is.

Drie combinaties van condities bleken samen te hangen met hele goede prestaties (zie tabel 1). Onder hele goede prestaties verstaan we dat de projecten op tijd en binnen budget gerealiseerd waren en dat er sprake was van value for money. Dit zijn de gangbare criteria om het succes van (PPS-)projecten vast te stellen. Value voor money (meerwaarde) kan overigens heel verschillend worden opgevat. Vanuit een financieel-economische benadering gat het daarbij om efficiency: dezelfde resultaten tegen lage kosten of meer functionaliteiten voor dezelfde prijs. Meerwaarde kan echter ook breder worden opgevat en zaken als innovatie, leerervaringen en verbeterde relaties behelzen. Deze zijn moeilijker vast te stellen. Vandaar dat we ook een meer kwalitatieve beoordeling van uitkomsten en prestaties hanteerden: de mate waarin de geïnterviewde betrokkenen tevreden waren over de uitkomsten van het project, in bredere zin dan alleen in tijd en geld.

Allereerst vonden we projecten waarbij de combinatie van vertrouwen tussen partners (een zachte conditie) en goede, vooraf gemaakte afspraken over de risicoverdeling (een harde conditie) voldoende tot zeer goede prestaties in PPS-projecten hebben geleid. Een risicoverdeling waarbij niet alle risico's toebedeeld zijn aan de private partner, vormt een goede basis voor de samenwerking, omdat zij gezamenlijk de lasten van het project dragen. Vertrouwen is vervolgens voldoende om gedurende het proces om te gaan met onverwachte omstandigheden

3 QCA is een methode die een systematische analyse mogelijk maakt van een groter aantal cases dan bij een gewone kwalitatieve vergelijkende gevalsstudiet. Een QCA bestudeert het gecombineerde effect van condities (in plaats van individuele variabelen te testen) om zo recht te doen aan de complexiteit van mogelijke causale relaties. Een QCA gaat uit van equifinaliteit, waarbij er verschillende, elkaar niet uitsluitende, paden zijn die naar eenzelfde uitkomst kunnen leiden. 
in het project. Een tweede succesvolle combinatie van condities bestond uit een goede risicoverdeling, strikt contract management (beide harde condities) en een goed conflictmanagement (een zachte conditie). Deze combinatie benadrukt het belang van goede afspraken over het verdelen van de risico's en het omgaan met conflicten en het belang van het handhaven van deze afspraken. Vertrouwen is hierbij geen noodzakelijke voorwaarde voor een goede performance. De derde combinatie van condities die we vinden bij succesvolle PPS-projecten, bestaat uit condities die bij een relationele benadering horen. In dit geval zijn de 'zachte' relationele condities vertrouwen en conflictmanagement gecombineerd met de afwezigheid van strikt contractmanagement. Dit is voldoende voor een succesvolle samenwerking. Deze combinatie benadrukt het belang van sociale relaties tussen publieke en private partners in PPS-projecten. Bijzonder aan deze combinatie is dat de afwezigheid van strikt contractmanagement een noodzakelijke voorwaarde is voor succes. De afwezigheid van strikt contractmanagement geeft beide partners de ruimte om oplossingen voor eventuele problemen te bedenken, die bij strikt contractmanagement niet mogelijk zouden zijn geweest. Het zorgt zodoende voor flexibiliteit.

Tabel 1 Combinaties van condities voor excellente performance

\begin{tabular}{llcll}
\hline & \multicolumn{2}{l}{\begin{tabular}{l}
\multicolumn{2}{l}{ 'Harde' contractuele condities } \\
Strikt contract- Risico-allocatie \\
management
\end{tabular}} & $\begin{array}{l}\text { 'Zachte' relationele condities } \\
\text { Conflict- } \\
\text { management }\end{array}$ & Vertrouwen \\
\hline Combinatie I & $\checkmark$ & & $\checkmark$ \\
Combinatie 2 & $\checkmark$ & $\checkmark$ & $\checkmark$ & \\
Combinatie 3 & $x$ & & $\checkmark$ & $\checkmark$ \\
\hline
\end{tabular}

Hoewel in discussies over sturing van PPS-projecten vaak de nadruk ligt op of het belang van een goed contract en strikt contractmanagement, óf van sturing op zachte aspecten, laat onze analyse van 25 Vlaamse en Nederlandse projecten dus zien dat er meerdere succesvolle combinaties van contractuele en relationele sturingscondities zijn (vergelijk Algemene Rekenkamer, 2013). Interessant is daarbij dat er wel een combinatie is met uitsluitend zachte, relationele condities, maar geen combinatie met uitsluitend harde, contractuele condities. Contractuele condities leiden alleen tot heel goede prestaties indien ze gecombineerd worden met zachte, meer relationele condities.

\section{Conclusie}

In de zoektocht naar slimme sturingsarrangementen voor PPS zijn we de afgelopen jaren zeker verder gekomen. We weten nu uit praktijkervaringen, maar ook uit onze onderzoeksresultaten, dat simpel sturen op harde factoren - zoals een strikt contractmanagement en de risico-allocatie - niet de oplossing is. PPS-projecten zijn complex en komen tot stand in een veranderende omgeving. Vertrouwen en flexibiliteit zijn cruciaal om deze projecten tot een succes te maken. Zowel 
in de wetenschap als de praktijk wordt het belang erkend van een verschuiving van contractuele naar relationele sturingsmechanismen. De omarming van de nieuwe markvisie door overheid en marktpartijen is daar een uitdrukking van. Of dat ook tot een andere praktijk en betere PPS-projecten leidt, is echter niet zeker. De Marktvisie bijvoorbeeld is op het moment niet veel meer dan een intentieverklaring. De Marktvisie omschrijft welk gedrag wenselijk is, maar biedt weinig concrete handvatten als het erom gaat hoe op goede relaties en vertrouwen gestuurd kan worden. Onderzoeksbevindingen, literatuur over sturing van samenwerking en discussies in de praktijk suggereren dat bij relationele sturing in het kader van PPS in ieder geval gedacht kan worden aan het maken van procesafspraken tussen partijen over hoe om te gaan met interpretatieverschillen, veranderende omstandigheden, conflicten en te vervullen rollen. Daarnaast zijn platforms nodig waar publieke en private partijen een voortdurende dialoog kunnen voeren en gezamenlijke teams kunnen vormen (vergelijk Hueskes et al., 2016; Klijn \& Koppenjan, 2016; Sanders, 2018; Warsen et al., 2017). Management dient behalve op inhoud ook gericht te zijn op de opbouw van goede verhoudingen, vertrouwen, het samenbrengen van de juiste persoonlijkheden, de vorming van een gemeenschappelijke identiteit en de zorg voor continuïteit. Duidelijk is ook dat deze relationele sturingswijzen eisen stellen aan de vaardigheden en persoonlijkheidskenmerken van managers aan zowel publieke als private zijde. Over de organisatorische condities waaronder deze sturingswijzen kunnen opbloeien, is nog weinig bekend. Duidelijk is wel dat relationele sturing de tekortkomingen van 'harde' condities zoals een slecht contract, een ontoereikend budget, de afwezigheid van steun van publieke en private achterbannen en een onmogelijke opdracht, nooit kan compenseren.

\section{Literatuur}

Algemene Rekenkamer. (2013). Contractmanagement bij DBFMO-projecten. Den Haag: Algemene Rekenkamer.

Commissie Private Financiering van Infrastructuur. (2008). Op de goede weg en het juiste spoor. Den Haag. Verkregen op 5 februari 2018 via https://anzdoc.com/queue/op-degoede-weg-en-het-juiste-spoor.html

Ham, H. van, \& Koppenjan, J.F.M. (red.). (2002). Publiek-private samenwerking bij transportinfrastructuur: Wenkend of wijkend perspectief? Utrecht: Lemma.

Hazeu, C.A. (2007). Institutionele economie: een optiek op organisatie- en sturingsvraagstukken. Bussum: Coutinho.

Hodge, G., \& Greve, C. (2005). The challenge of public-private partnerships. Cheltenham: Edward Elgar.

Hodge, G., Greve, C., \& Boardman, A.E. (2010). International handbook on public-private partnership. Cheltenham: Edward Elgar.

Hueskes, M., Koppenjan, J., \& Verweij S. (2016). Publiek-private samenwerking in Nederland en Vlaanderen: Een review van veertien proefschriften. Bestuurskunde, 25(2), 90-104.

Kenniscentrum PPS. (1998). Eindrapport Meer Waarde door SamenWerken. Den Haag: Ministerie van Financiën. 
Klijn, E.H. (2009). Public-private artnerships in the Netherlands: Policy, projects and lessons. Economic Affairs, 29(1), 26-32.

Klijn, E.H., \& Koppenjan, J.F.M. (2016). The impact of contract characteristics on the performance of public-private partnerships (PPP's). Public Money \& Management, 36(6), 455-462.

Koppenjan, J.F.M., \& Jong, M. de. (2018). The introduction of public-private partnerships in the Netherlands as a case of institutional bricolage: The evolution of an AngloSaxon transplant in a Rhineland context (1986-2016). Public administration (forthcoming). doi:10.1111/padm.12360

Kort, I.M., Verweij, S., \& Klijn, E.H. (2016). In search for effective public-private partnerships: An assessment of the impact of organizational form and managerial strategies in urban regeneration partnerships using fsQCA. Environment and Planning C: Politics and Space, 34(5), 777-794.

Ministerie van Financiën. (2016). Voortgangsrapportage DBFM(O) 2015, 2016-2017. 3 oktober 2016. Den Haag: Ministerie van Financiën.

Poppo, L., \& Zenger, T. (2002). Do formal contracts and relational governance function as substitutes or complements? Strategic Management Journal, 23(8), 707-725.

Rijkswaterstaat. (2016 ${ }^{\mathrm{A}}$ ). Marktvisie 2016-2020. Den Haag. Verkregen op 5 februari 2018 via https://marktvisie.nu/.

Rijkswaterstaat. (2016 ${ }^{\mathrm{B}}$ ). Samen met de markt. Den Haag. https://staticresources. rijkswaterstaat.nl/binaries/Samen\%20met\%20de\%20markt\%20-\%20strategische \%20doorvertaling\%20Rijkswaterstaat\%201.1_tcm21-78981.pdf

Sanders, M. (red.). (2018). Publiek-private samenwerking: Kunst van het evenwicht. Den Haag: Boom Lemma.

Steijn, A.J., Klijn, E.H., \& Edelenbos, J. (2011). Public private partnerships: Added value by organizational form or management? Public Administration, 89(4), 1235-1252.

Warsen, R., Koppenjan, J.F.M., \& Klijn, E.H. (2017). Hard and soft conditions for successful public-private partnerships: is it the mix that matters? Paper presented at the sixth International joint conference of the International Public-Private Partnership Scholars Network. 21-22 september, 2017. Limerick, Ireland.

Warsen, R., Nederhand, J., Klijn, E.H., Grotenbreg, S., \& Koppenjan, J.F.M. (2018). What makes public-private partnerships work? Survey research into the outcomes and the quality of cooperation in PPPs. Public Management Review. Online first. doi: 10.1080/14719037.2018.1428415 